\title{
One or more water demand patterns? - Calibration of the selected water network model
}

\author{
Beata Kowalska ${ }^{1, *}$, Dariusz Kowalski ${ }^{1}$, Pawet Suchorab ${ }^{1}$, and Matgorzata Iwanek ${ }^{1}$ \\ ${ }^{1}$ Lublin University of Technology, Faculty of Environmental Engineering, Nadbystrzycka 40B, 20-618 Lublin
}

\begin{abstract}
Calibration is one of the key steps in creating a numerical model of water supply networks. Calibration is performed on the basis of the results of the field measurement campaign and it should result in a consistent match of the simulation results with the results of the measurements. In the article the process and the results of the calibration of the selected water network model with the use a single (generalized) water demand pattern and using 11 patterns prepared for selected, characteristic consumers have been presented. Calibration was performed using the trial and error method in EPANET 2.0 and the optimization method in WaterGEMS.
\end{abstract}

\section{Introduction}

Increased complexity of water supply systems contributed to popularizing the use of professional computer software for managing a water supply company. Computer models support planning, designing, modernizing and operating vast water supply networks [1-3]. The quality of simulation analyses largely depends on the quality of model design, which is reflected in: representation of the structure of particular elements, identification of water supply system elements, water demand models and the parameters of water supply network [4,5]. The required degree of model simplification depends on the goal of simulations (hydraulic conditions, quality changes, energy cost). In the case of the existing networks, a model must be calibrated to function properly. Calibration involves adjusting the parameters of particular model elements, so that the obtained calculation results correspond to the actual conditions in a network [6,7]. During the calibration of hydraulic models, the following parameters may be subjected to adjustment: pipe roughness coefficient, values and patterns of water demand and status of gate valves. Thus far, there are no unequivocal matching criteria for the above-mentioned parameters. Certain recommendations pertaining to static and dynamic models were devised in the United Kingdom and the United States [8]. The difficulties in achieving a match between the results obtained on the basis of a model and the results from measurements may stem from the uncertainty of model structure, uncertainty of the calculation method as well as the uncertainty of the devices used for measurement and control.

One of the most important factors having an influence on the simulation calculations is the correct allocation of water demand in particular junctions of the hydraulic model. This is a difficult task due to the variability of water demand in various time cycles and the diversity of their distribution depending on the recipient category. Correct inclusion of water demand changes by various recipient categories is especially important in Extended Period Simulations (EPS) models.

The temporal variability of water demand may be analyzed over multiple years, annually, seasonally, monthly, weekly, as well as daily and hourly. Diversification both in the daily and hourly water demand is dependent on numerous factors. They include the regional diversification, economic conditions, sociological factors as well as highly important demographic status and the industrial development in a given region [9].

The presented work made an attempt of calibrating an existing hydraulic model of a selected water supply network with the use of individual water demand patterns devised for the selected recipients and comparison of the results with the ones obtained from the calibration conducted with a general pattern. The calculations were carried out in EPANET 2.0 (US EPA) and WaterGEMS software by Bentley. The assessment of matching was additionally conducted with the use of statistical analyses performed with Statistica 13.1 software package by StatSoftPolska.

\section{Object description and research methodology}

The analyzed water supply network supplies approximately 53 thousand residents and about 4300 economic entities, mainly representing services, trade, gastronomy, administration centers, education and health care. The water supply network uses groundwater, the well water is supplied untreated to two field storage tanks. Then, it is transmitted via suction pipeline with the diameter of $\varnothing 300$ and supplied to the water supply

*Corresponding author: b.kowalska@pollub.pl 
network by means of a pumping station. The water supply pipelines, with the length of roughly $170 \mathrm{~km}$ are mainly made of grey cast iron and ductile iron, asbestos cement, steel, polyethylene and polyvinyl chloride.

The conducted analyses were based on the numerical model of the water supply network prepared earlier, presenting the geometrical structure of this network, location of objects, diameters, pipe roughness, as well as levels of foundation. The model was devised as "basic", i.e. containing all the water mains and branches, without the house connections. It comprises 2785 junctions and 2987 connecting pipes. The included water demand corresponds to an average daily value. The daily distribution of water demand (general pattern) was devised on the basis of readouts from two flow meters located at the pumping station outlet.

In order to devise the data pertaining to individual water recipients, following the analysis of water recipient register and discussions with local Municipal Water and Sewerage Company, 11 categories were assumed: shop, kindergarten, sports hall, high multifamily buildings, medium multi-family buildings, shopping centre, office, hotel, detached houses, terrace houses, small production plant with low water demand. The patterns were devised as part of diploma papers $[10,11]$. Owing to the applied electronic devices for remote radio readout of water meters, it was possible to collect data for 48 hours with hourly intervals. The study lasted for 15 days, including two weekends.

For the purpose of the hydraulic model calibration, pressure measurements were carried out in 15 measurement locations. The pressure meters were installed on selected fire hydrants and one was placed at the pumping station outlet. The pressure in the selected measurement locations was taken using Cell-Box-H meters, equipped with loggers saving the data. The flow rate in 9 locations was measured using Porta Flow 300, Rota Yokugawa 80 and HydrINSultrasound flowmeters. Additionally, the existing water- and flowmeters, installed permanently in the pumping station, were used. At the first stage of analyses, the hydraulic model built using EPANET 2.0 software was calibrated with the general pattern; then, individual patterns prepared for the afore-mentioned 11 recipient categories were introduced and the model was recalibrated in EPANET 2.0. Afterwards, the hydraulic model with introduced individual patterns was converted to WaterGEMS software and again calibrated with the available tools.

During the calibration of the hydraulic model of a water supply network in EPANET 2.0, an integrated calibration report module was utilized [12]. The calibration process was carried out using a trial and error method, which involved an attempt to obtain the best match between the results of measurement and model calculation. In this method, the pipe roughness, pressure at the pumping station outlet and the parameters of pressure-reducing gate valves were adjusted "manually". The calculated water demand was adjusted to the supply measured in the pumping station through a uniform daily peaking factor.
Calibration of the hydraulic model in WaterGEMS software by Bentley, was conducted in the proprietary Darwin Calibrator module [13]. In this case, the automatic calibration utilizing the genetic algorithm with three calibration criteria, including: Minimize Difference Squares; Minimize Difference Absolute Values and Minimize Maximum Difference, was selected. Calibration was carried out based on the same pressure and flow rate measurement results used in EPANET 2.0. The calibration involved adjusting the pipe roughness coefficient (ROUGHNESS) and the water demand in a junction (DEMAND). In the genetic algorithm, the variability of pipe roughness and junction water demand ranging from 0.5 to 1.5 of the initial value, was assumed.

\section{Research results and discussion}

The first stage of research involved calibration of the hydraulic model (pressure and flow rate) in EPANET 2.0 software. The calibration was conducted using a single, general pattern of water demand; then, individual patterns (prepared on the basis of 11 characteristic types of recipients) were introduced and the calibration was repeated. When the calculations were finished, a combined calibration report was generated for the analyzed cases. The obtained coefficients of determination $r^{2}$, reflecting the matching degree of linear regression to the data, virtually did not differ from one another. Their values, exceeding 0.9 suggest a very good match. However, one should remember that the quality evaluation of the calibration obtained with EPANET 2.0 software does not reflect the actual matching degree of model parameters, because it involves the mean values.

The next step included calibration in WaterGEMS software, which utilized converted hydraulic model with introduced individual patterns and a genetic algorithm. The coefficient of determination obtained on the basis of non-averaged flow rate measurement spots, reached $r^{2}=0.872$ and reflected the actual conditions in the analyzed water supply network better. For the sake of comparison, the $r^{2}$ for mean values was calculated as well, yielding a nearly identical value to EPANET 2.0 (Table 1). This proves that averaging does not reflect the actual matching degree of the model to the measured values.

Table 1. Comparison of $r^{2}$ after calibration.

\begin{tabular}{|c|c|c|c|c|}
\hline \multirow{4}{*}{$\begin{array}{c}\text { Para- } \\
\text { meter }\end{array}$} & \multicolumn{2}{|c|}{$\begin{array}{c}\text { EPANET 2.0 } \\
\text { peneral }\end{array}$} & \multicolumn{3}{c|}{ WaterGEMS } \\
\cline { 2 - 5 } & \multicolumn{4}{|c|}{ Individual patterns } \\
\cline { 2 - 5 } & \multicolumn{3}{|c|}{$\boldsymbol{r}^{2}$ for } \\
\cline { 2 - 5 } & mean values of parameters & $\begin{array}{c}\text { not averaged } \\
\text { parameters }\end{array}$ \\
\hline Flow rate & 0.956 & 0.967 & 0.966 & 0.872 \\
\hline Pressure & 0.998 & 0.998 & 0.999 & 0.980 \\
\hline
\end{tabular}


The coefficient of determination obtained on the basis of all measurements (without averaging) - enables a general assessment of the quality of conducted calibration. In order to perform more detailed analyses, calculations were carried out in the measurement locations in which pressure and flow rate were measured during a campaign. The differences between the calculated values and the ones measured in particular locations could be observed on the graphs of these changes in time. Fig. 1 and Fig. 2 present the results for exemplary locations (junction, pipe) designated in the model as J2502 and P2417. Both the junction and the pipe represent "average" differences between the calculated and measured values. In the remaining locations the differences were lower, sometimes almost indiscernible, or higher from the presented values.

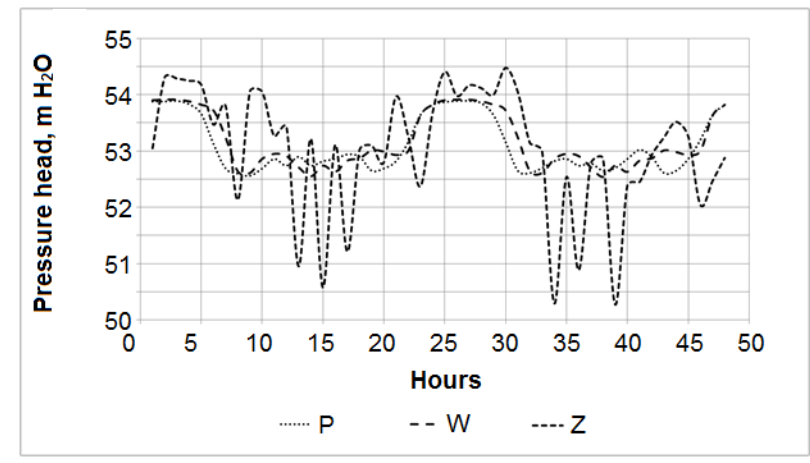

Fig. 1. Comparison of the results of simulation of pressure head changes in node J2502 using general pattern (P) and individual patterns $(\mathrm{W})$ with measurement results $(\mathrm{Z})$.

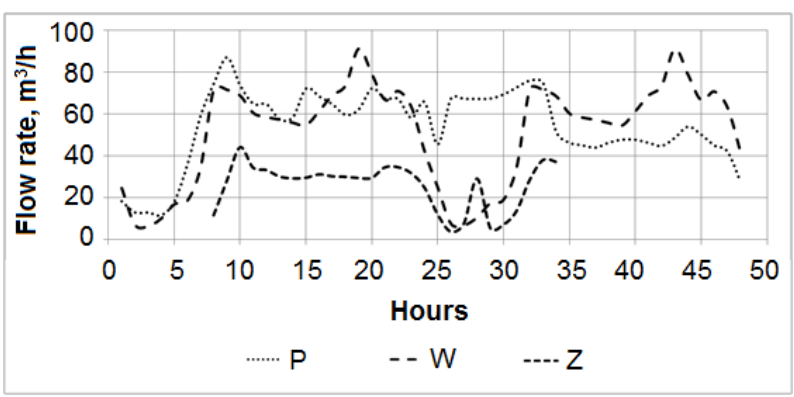

Fig. 2. Comparison of results of flow rate simulations in pipe P2417 using general pattern $(\mathrm{P})$ and individual patterns (W) with measurement results $(\mathrm{Z})$.

In order to picture the matching degree between the measured and calculated values in the measurement locations for different types of patterns (general and individual), statistical analyses were performed in Statistica 13.1 software package. The Figs 3, 4 and 5 present the matching degree of the pressure in junction J2502 analyzed earlier, following calibration in EPANET 2.0 and WaterGEMS.

The value of the coefficient of correlation while using the general pattern was $r=0.38654$ and was lower than the value obtained after the introduction of individual patterns $\quad(r=0.52647 \quad$ EPANET 2.0, $r=0.63866$ WaterGEMS). Therefore, making the water demand patterns more specific contributed to positive results.

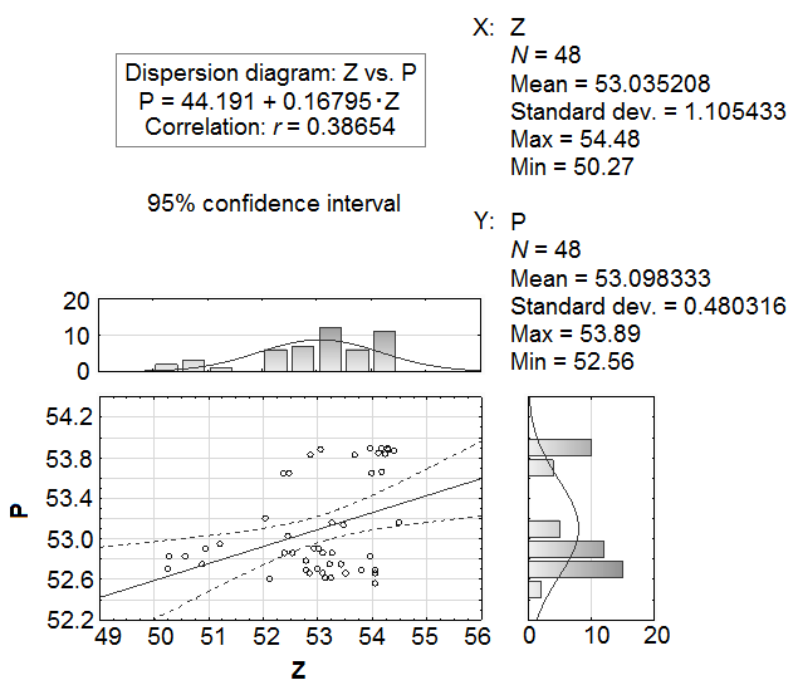

Fig. 3. Comparison of the results of the simulations of pressure head changes in node J2502 using general pattern (P) with measurement results $(Z)$.

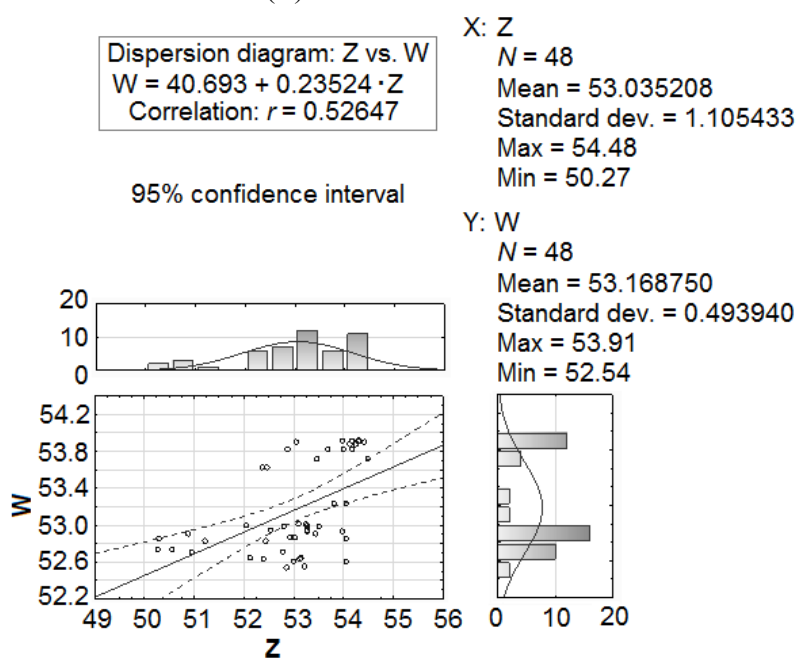

Fig. 4. Comparison of results of simulation of pressure head changes in node J2502 using individual patterns (W) with measurement results (Z) (EPANET 2.0).

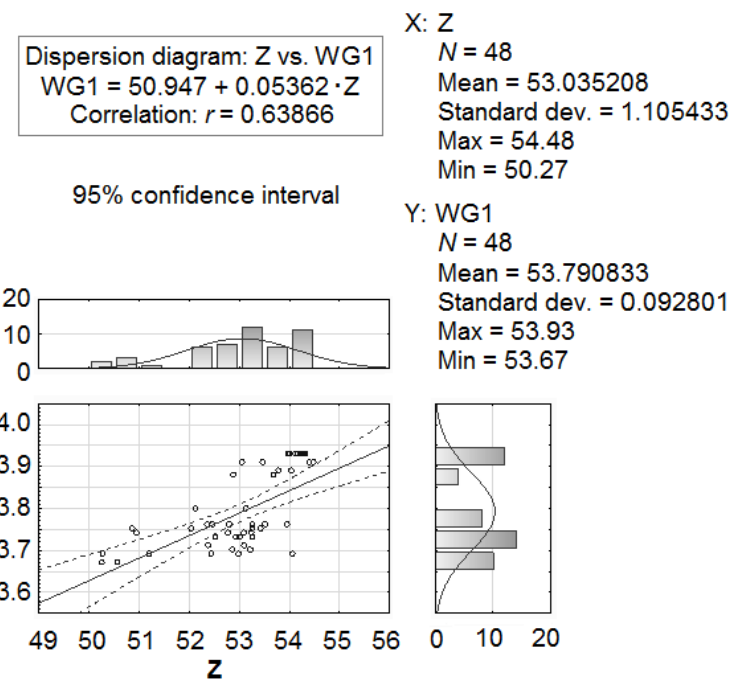

Fig. 5. Comparison of results of simulation of pressure head changes in node J2502 using individual patterns (WG1) with measurement results $(\mathrm{Z})$ (WaterGEMS). 
However, taking into account all measurement locations, it is difficult to unequivocally evaluate the influence of implemented changes, because in some cases the results were almost the same.

The Fig. 6 presents (as an example) the matching degree of flow rate in pipe P2417 (with individual patterns), which was also analyzed earlier. Using the general pattern, virtually no correlation was observed. Similarly to the previous case, it is difficult to unequivocally evaluate the influence of implementing individual patterns, because in other junctions, the situation varied; sometimes the differences were almost indistinguishable.

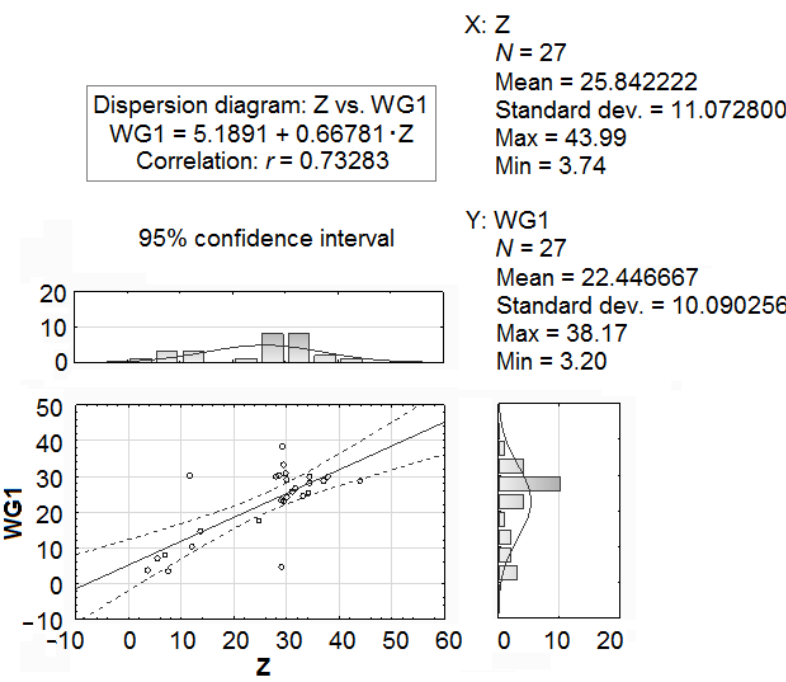

Fig. 6. Comparison of flow rate simulation results in pipe P2417 using individual patterns (WG1) with measurement results $(\mathrm{Z})$ (WaterGEMS).

\section{Conclusions}

- Taking into account the results of analyses conducted in the work, which aimed at evaluating the impact of applying individual water demand patterns on the calibration results, it can be stated that adding more details to the data introduced to the hydraulic model seems to be a right direction.

- Unfortunately, the calibration module of EPANET 2.0 software does not enable a correct evaluation of the matching degree of the analyzed variables. The reported values of coefficient of determination $r^{2}$ are unreliable, because they pertain to the averaged values; therefore, it was virtually impossible to observe the difference after the implementation of changes in the model under the conditions of considered water supply network.

- Application of the automatic calibration, utilizing genetic algorithms for calculations, which is included in WaterGEMS software, enabled to reflect the actual conditions in a water supply networkbetter. Moreover, the possibility of using the automatic calibration module facilitates and accelerates the calibration process, which is required each time changes are introduced to the existing model.

- The statistical analysesconducted using Statistica 13.1 software package in particular junctions of the model enabled to evaluate the differences in matching of the model data following the implementation of more detailed, individual water demand patterns. Slightly better results were obtained after the calibration in WaterGEMS. The fact that the obtained results were not always unequivocal could have stemmed, i.a. from the inconsistencies and omissions during the measurement campaign, e.g. lack of remote water meter readouts, which prevented a periodic synchronization of the water demand values with the values measured in the network. Hydrant tests were not carried out during the pressure measurementseither.

- To sum up, the obtained results confirm that calibration is an extremely difficult and complex process, and its quality depends on numerous factors. The obtained findings enabled to observe a slight improvement in the results following the introduction of more detailed individual water demand patterns, and thus may constitute the basis for further research, which should be verified in terms of the observed issues.

The Polish extended version of the paper was published in the journal Instal 7-8, 2017, p. 57-60.

\section{References}

1. I. Zimoch, Ochr. Środ. 30, 3 (2008) http://www.os.not.pl/docs/czasopismo/2008/Zimoch 3-2008.pdf

2. A. Bałut, J. Bylka, Instal 12, (2013)

3. I. Zimoch, Ochr. Środ. 34, 4 (2012)

4. A. Kotowski, A. Pawlak, P. Wójtowicz, Ochr. Środ. 32, 2 (2010)

5. I. Zimoch, E. Łobos, Environ. Prot. Eng. 36, 4 (2010) http://epe.pwr.wroc.pl/2010/zimoch_4-2010.pdf

6. Z. Siwoń, W. Cieżak, Instal 1, (2008)

7. Z. Kapelan, Calibration of Water Distribution System Hydraulic Models (PhD thesis, University of Exeter 2002)

8. AWWA Engineering Computer Applications Committee, Calibration Guidelines for water distribution system modeling (1999), Reprinted from Proceedings of the AWWA Information Management and Technology Conference, New Orlean, Louisiana, April 1999

9. E. Kozłowski, B. Kowalska, D. Kowalski, D. Mazurkiewicz, Arch. Civ. Mech. Eng. 18, 1 (2018)

10. J. Połeć, Ocena warunków hydraulicznych wybranej strefy wodociagu $z$ uwzględnieniem odbiorców indywidualnych (MSc thesis, Lublin University of Technology, 2016)

11. P. Wyglądała-Szarek, Analiza warunków hydraulicznych $w$ oparciu o wzorce indywidualne we fragmencie miejskiej sieci wodociagowej (MSc thesis, Lublin University of Technology, 2016)

12. A.L. Rossman, EPANET 2 Users Manual (U.S. EPA, Cincinnati 2000)

13. T. Walski, D. Chase, D. Savič, W. Grayman, S. Beckwith, E. Koelle, Advanced Water Distribution Modeling and Management (Bentley Institute Press, Exton, Pennsylvania USA, 2007) 